\title{
Stage IIIA Cervical Cancer AJCC v8
}

National Cancer Institute

\section{Source}

National Cancer Institute. Stage IIIA Cervical Cancer A/CC v8. NCI Thesaurus. Code C139750.

Stage IIIA includes: T3a, Any N, M0. T3a: Tumor involving the lower third of vagina but not extending to pelvic wall. M0: No distant metastasis. (AJCC 8th Ed.) 